with the latest methods for separating populations using serology and X-ray fluorescence spectometry.

The following five chapters I am afraid contribute nothing new to the field. Many cheaper books (an important consideration for undergraduates), such as those produced for the International Biological Programme, deal with age and growth, population estimation, mortality, recruitment and yield in as much detail. when considering habitat improvement, pond management, screens and guiding devices and fish ways, subjects given considerable space in their earlier book. There is a slight imbalance at times (a result of three authors?), for example pollution is "written off" in four pages, although a two and a half
The authors come into their own

page bibliography on the subject follows the chapter. Yet, under Control of Undesirable Species (Chapter 18), we have a 2-page description (pp263265) of the new piscicide antimycin.

There are two useful chapters on the Role of Hatchery-reared Fish and Stocking, although the literature citations are practically all of work carried out in North America; this is a general criticism of the bibliographies at the end of all the chapters.

This is a useful working text for undergraduates, which I shall certainly suggest mine read. It is difficult, however, to recommend its purchase at its present price. I suggest that its contents be slightly reduced, perhaps by removing chapters 3,9 and 11 , and released as a paperback. It will then serve a very useful role. Derek Mills

\section{Surface physics}

Surface Physics. (Oxford Physics Series.) By M. Prutton. Pp. viii +117. (Clarendon: Oxford; Oxford University: London, August 1975.) £2.75.

THE 'black magic' of surface effects is just starting to gell into science. Physicists have seen good spectroscopic evidence of the 'dangling bonds' or 'surface states' of which they have talked for years; and now diffraction experiments can identify the reconstruction of the lattice which take place if a layer of atoms is deprived of its neighbours on one side. The concepts, although exciting, are still complex and novel; and thus any attempt to present the physics of surfaces to the undergraduate requires a controlled style, a very firm grip of concepts and will also gain tremendously from deep immersion in the prevailing currents of research. Dr Prutton qualifies in all these departments and has produced a fascinating and readable text, covering a surprising amount in an inexpensive 117 pages. $\mathrm{He}$ also somehow manages to combine impartiality with an infectious enthusiasm.

For those solid-state device workers who may be preparing to rush precipitately to the bookshelves, it must quickly be said, however, that the systems covered here are all ultraclean vacuum-solid interfaces and the much more murky field of solid-solid interfaces will probably have to wait a long time before a similar burst of enlightenment manifests itself. Ultrahigh vacuum techniques have made possible a battery of methods (LEED, XPS, UPS, ELS, AES and FEM, to name a few acronymically) which have revolutionised our knowledge of vacuumsolid interfaces but which cannot pene- trate to internal interfaces. Even the device worker, however, can learn a great amount from this book about the detection of surface impurities and he can also begin to appreciate how the growth of thin films is so powerfully controlled by the surface forces described.

I particularly appreciated some clear explanations of Ewald sphere construction for two-dimensional 'nets' and the distinctions between ultraviolet and X-ray photoelectron spectroscopy. Most of the drawings are jewels of explanatory lore, the captions being nearly sufficient in themselves as a teaching instrument; the references to other texts are confined wherever possible to a few authoritative works.

Among the explanations which I found less than illuminating were those on field emission and the photoelectric effect. Here, surely, are two properties well suited for demonstrating both the ideal electronic behaviour of surfaces and some direct practical uses of clean vacuum-solid interfaces as, for example, in photomultipliers. The great body of work on the effect of alkali atom adsorbates on the electron affinity of surfaces would have fitted rather well into the scheme of the book but is not mentioned. This is, perhaps the most clear example of a tendency in the book to emphasise structural features at the expense of electronic poperties; another example is the very brief treatment of the surface state as an electronic level, in spite of some classic studies recently published by Spicer, Eastman and others.

With these reservations there is no doubt that this compact and inexpensive little book will engender the right kind of enthusiasm for and familiarity with surface physics in many universities and even sixth forms.

Andrew Holmes-Siedle
Mexikanischer Vulkane

Studien zur jungquartären Glazialmorphologie mexikanischer Vulkane. (Mexiko-Projekt der deutschen Forschungsgemeinschaft, Vol. VII.) Pp. 178. By Klaus Heine. (Franz Steiner: Wiesbaden, 1975.) Quarto, art. Hardback: DM82.00.

THIS work, based on an extensive field survey of the more accessible high volcanoes, sampling of sediments and mineralogical analyses, is extremely interdisciplinary. The geomorphological features are assigned to their relative sequence and absolute dates through the stratigraphical evidence afforded by intervening beds of pyroclastics and fossil soils. Both of these, being readily identifiable and very widespread in the region and often carrying at least limiting ${ }^{14} \mathrm{C}$ dates, enable correlations to be established between glacial features which are miles distant from each other, on more or less isolated volcanic piles up to $5,500 \mathrm{~m}$ in altitude.

At no time, it seems, did even valley glaciers extend below the $2,500 \mathrm{~m}$ contour, whereas the three present-day, barely surviving ice caps all lie above $4,700 \mathrm{~m}$. Five main glacier advances, marked by moraines, are recognised: MI, 38,000-32.000; MII, about 12,100; MIII, $1+2$, about $10000-9,000 ;$ MIV, c. 2,000; MV. $180-25$ yr b.p. These conclusions are supported by numerous sections distributed over a wide area described and figured in detail, and borne out by corresponding evidences on the four volcanoes most closely studied. (La Malinche. Iztaccíhuatl, Popocatépetl, Citlaltépetl.) Similar, but less complete, observations were made on a number of lesser peaks, which, although unglaciated today, show the signs of at least some of the late Pleistocene and Holocene events described.

A brave attempt is made to derive a palaeoclimatic explanation of the ground phenomena, which is, perhaps, less convincing than the results of the painstaking fieldwork. This is largely due to the very divergent views expressed in the climatological literature, so that any author is obliged to espouse one or other mutually exclusive theories.

An enormous Bibliography is provided of relevant literature, making this a valuable work of reference and a worthy successor to previous volumes in the series.

I. W. Cornwall 